\title{
Green chemistry synthesis of biocompatible ZnS quantum dots (QDs): their application as potential thin films and antibacterial agent
}

\author{
Jejiron Maheswari Baruah ${ }^{1} \cdot$ Sanjeeb Kalita $^{2} \cdot$ Jyoti Narayan $^{1}$ D
}

Received: 16 February 2018 / Accepted: 15 March 2019 / Published online: 27 March 2019

(c) The Author(s) 2019

\begin{abstract}
We are presenting here the synthesis of quantum dots (QDs) of direct band gap semiconductor, cubic ZnS through modified green chemistry-mediated chemical precipitation reaction. Green chemistry-synthesized (GCS) ZnS QDs were characterized using powder X-ray diffraction and high-resolution transmission electron microscope techniques. Analysis of results, revealed by both the techniques for the synthesized QDs, is complementary as far as the size range (2-6 nm) of ZnS QDs is concerned. UV-Vis spectrophotometric spectrum $\left(\lambda_{\max }=314 \mathrm{~nm}\right)$ showed a conspicuous blue shift than the bulk. The Fouriertransformed infrared spectra convincingly reported a $\mathrm{Zn}-\mathrm{S}$ bond stretching frequency at $649 \mathrm{~cm}^{-1}$. The characterized QDs were subjected to the preparation of thin films over $\mathrm{SiO}_{2}$ template $(57 \mathrm{~nm}$ thickness) using photoresist spin coating technique at the ambient condition. The surface topology of nanoscale-thick films was studied by atomic force microscope (roughness parameter $-33.28 \mathrm{~nm}$, rms; for a scan area of $3.48 \times 3.48 \mu \mathrm{m}^{2}$ ). The symmetrical (skewness $=1.68$ ) and random distribution (kurtosis $=2.93$ ) of the peaks and valleys revealed the nanoscale-thick films of ZnS QDs. Zeta potential $(-9.2 \mathrm{mV})$ fairly proved stable existence of ZnS QDs. The GCS QDs were found to be non-toxic toward L929 mouse fibroblastic cells and human erythrocytes. However, they demonstrated significant inhibitory effects against seven bacterial pathogens with an average zone of inhibition of $1.5 \mathrm{~cm}$ at $100 \mu \mathrm{g} / \mathrm{ml}$ concentration. The minimum inhibitory concentrations determined were in the range of 75 to $125 \mu \mathrm{g} / \mathrm{ml}$ for gram-positive and 100 to $150 \mu \mathrm{g} / \mathrm{ml}$ for gram-negative bacterial pathogens.
\end{abstract}

Keywords Zinc sulfide quantum dots · Green synthesis · Thin films · Biocompatibility · Antibacterial effect

\section{Introduction}

Today's world is significantly pursuing the research that indulges in the design, development and implementation of chemical products and processes to reduce the use and

Electronic supplementary material The online version of this article (https://doi.org/10.1007/s40089-019-0270-x) contains supplementary material, which is available to authorized users.

Jyoti Narayan

jnarayan.nehu@gmail.com

1 Synthetic Nanochemistry Laboratory, Department of Basic Sciences and Social Sciences (Chemistry Division), School of Technology, North Eastern Hill University, Shillong 793022, India

2 Drug Discovery Lab, Biological and Chemical Sciences Section, Life Sciences Division, Institute of Advanced Study in Science and Technology (An Autonomous Institute Under Department of Science and Technology Government of India), Guwahati, Assam 781035, India generation of products that are hazardous to human health and environment [1-3]. The sustainable and renewable green energy, as an alternative to carbon-emitting fossil fuels, has become the main target of green energy researchers [4-6]. Greenhouse gases are the main by-products of carbonbased traditional energy sources. To eliminate hazardous environmental issues, photovoltaic solar cells (PVSCs) apart from nuclear, thermal and wind energy have gained the momentum [7]. Presently, quantum dot-sensitized solar cell (QDSSC) is gaining the preference as the most effective PVSC [8-10], although it is still at the investigation level only.

The semiconducting quantum dots (QDs) have full access to the whole solar spectrum. They have the additional advantage of production of high quantum yield by the generation of multiple excitons [11-16]. Semiconducting QD (SQD) metamaterial has potential applications in the field of smart LEDs (light emitting diodes) [17-20], photocatalytic activity [21-24], space science [25, 26], biological fields such as biosensors, biomarkers and as bio-tagging agents [27-30]. 
It has been observed that SQDs of IIB-VIA groups are efficient metamaterial for PVSC applications due to their direct band gap, large excitons binding energy [31, 32] and a high index of refraction [33]. The literature reveals that the nanometer range of the particles enhances the properties of semiconducting metamaterial due to its quantum confinement effect [34]. Among the nano-materials of group IIB-VIA, zinc sulfide ( $\mathrm{ZnS}$ ) QDs have wide and direct band gap $E_{\mathrm{g}}=3.58 \mathrm{eV}$ at $300 \mathrm{~K}$ (bulk cubic crystals), which might make it suitably promising optical material toward the design of solar cell. Keeping in view the above advantage and multi-faceted applications, the present work has been taken into consideration. The present work reports the green synthesis of SQDs of $\mathrm{ZnS}$ at the ambient conditions. The eco-friendly synthesis involves the use of water-soluble precursors and capping agents, resulting in the formation of non-hazardous by-products which can further easily be removed by repeated washing with water. The green chemistry synthesis (GCS) process was found to be cost-effective, reproducible, energy-efficient and sustainable. It has been observed that the mechanized thin film solar cells (TFSCs) are much thinner and light weighted as compared to the traditional first-generation solar cells [35, 36]. This has led to the development of thin films using nano-materials proving better efficiency as compared to the previously available one. The thin films are considered to be third-generation [37-42] engineered device that can hold the desired PVSC applications quite well. Keeping in view this, the colloidal solution of $\mathrm{ZnS}$ nanoparticles was used for the fabrication of variable nano-sized $(<100 \mathrm{~nm})$ thin films in order to study their structural morphology and surface topology. In order to make the thin films eco-friendly, the QDs used for making thin films need to be analyzed for their biocompatibility and antibacterial activity. Thus, green-synthesized QDs of $\mathrm{ZnS}$ semiconducting metamaterial were further subjected to the studies on their biocompatibility and zone of inhibition (ZOI) over human erythrocytes, mouse fibroblast cells and seven (gram positive and gram negative) bacterial pathogens, respectively.

\section{Experimental section}

\section{Materials and methods}

All the chemicals used during the synthesis that were of analytical grade are reported under Supplementary information. Series of green synthetic reactions were carried out by either changing the concentration of precursors or capping reagent. At first, the $\mathrm{Zn}\left(\mathrm{NO}_{3}\right)_{2} \cdot 6 \mathrm{H}_{2} \mathrm{O}(1 \mathrm{M}, 1.487 \mathrm{~g})$ was added to $5 \mathrm{ml}$ of double distilled water (A). The solution was stirred well on a magnetic stirrer at room temperature $(\mathrm{pH}=6.1)$ for about $5 \mathrm{~min}$ in order to get a homogeneous solution.
In the meantime, D-glucose (2 M, $1.9816 \mathrm{~g})$ solution was prepared in $5 \mathrm{ml}$ of double distilled water (B). Solution B was added dropwise to the solution A till a uniform homogeneous mixture was obtained $(\mathrm{pH}=6.3)$. At this stage, the aqueous solution of $\mathrm{Na}_{2} \mathrm{~S}(2 \mathrm{M}, 0.7808 \mathrm{~g})$ in $5 \mathrm{ml}$ double distilled water was added dropwise to the precursor solution till the entire solution became white in color $(\mathrm{pH}=5.4)$. The resultant solution was refluxed for an hour. A yolk-colored solution was observed.

Reaction scheme

$$
\begin{gathered}
\mathrm{Zn}\left(\mathrm{NO}_{3}\right)_{2} \cdot 6 \mathrm{H}_{2} \mathrm{O}+\mathrm{Na}_{2} \mathrm{~S}+D \text {-Glucose } \frac{\mathrm{H}_{2} \mathrm{O}}{\text { reflux } / 1 \mathrm{~h}} \mathrm{ZnS} \text { QDs } \\
\mathrm{Zn}\left(\mathrm{NO}_{3}\right)_{2} \cdot 6 \mathrm{H}_{2} \mathrm{O}+D \text {-Glucose } \stackrel{\mathrm{H}_{2} \mathrm{O}}{\longrightarrow} \mathrm{Zn}^{+2}-D \text {-Glucose } \\
\mathrm{Na}_{2} \mathrm{~S} \rightarrow \mathrm{S}^{-2}
\end{gathered}
$$

The resultant solution was subjected to centrifugation at $14,000 \mathrm{rpm}$, and the precipitate formed was washed several times with double distilled water $(\mathrm{pH}=7.0)$ and acetone, respectively. The purified end product so formed was dried overnight by keeping in a vacuum desiccator. The dried sample was used for further characterization.

\section{Instruments used for characterization}

The X-ray diffraction patterns of synthesized ZnS QDs are recorded with Bruker D8 Advance X-ray diffractometer. The primary X-ray wavelength $\mathrm{Cu}-\mathrm{K} \alpha 1$ is at $1.5405 \AA$ with a $2.2-\mathrm{kW}$ power source. The sample was recorded in a wide range of Brag's angle from $5^{\circ}$ to $90^{\circ}$ to get the best profile for the sample. The high-resolution transmission electron micrographs are obtained from JEOL JEM-2100 Transmission Electron Microscope with a resolution of $1.9 \AA$ to $1.4 \AA$. The images are captured with a $2.672 \times 2.672 \mathrm{k}$ highresolution CCD camera at $200 \mathrm{kV}$ acceleration voltage. The absorption spectrum $\left(\lambda_{\max }\right)$ is recorded with Ocean Optics DH-2000-BAL UV-visible spectrophotometer. The FTIR spectrum is recorded with PerkinElmer FTIR spectrophotometer (Spectrum 400) in the range of $400-4500 \mathrm{~cm}^{-1}$. The zeta potential was measured with Anton Paar Litesizer 500.

\section{Preparation of thin films}

The variable concentration of purified and characterized nano-crystals of $\mathrm{ZnS}$ was redispersed in double distilled water followed by sonication for about $10 \mathrm{~min}$. Variable volumes of sonicated $\mathrm{ZnS}$ colloidal solution were used for making nano-sized thin films using photoresist spin coater (Ducom, PR-6-M2) at different rpm over well-cleaned $\mathrm{SiO}_{2}$ templates. The thin films were dried at $50{ }^{\circ} \mathrm{C}$ for $5 \mathrm{~h}$. Dried thin films were subjected to analysis regarding their thickness and surface structure using film thickness measurement 
instrument (Filmetrics F20, thickness range $15 \mathrm{~nm}-70 \mu \mathrm{m}$; visible wavelength range from 380 to $1050 \mathrm{~nm}$ ) and atomic force microscope (AFM) (Nanosurf Easyscan 2 in dynamic mode), respectively. To analyze the surface roughness, $70-\mu \mathrm{m}$ scan head was used in AFM to record the inference in non-contact tapping mode using Tap190Al-G probe.

\section{Scheme for the analysis of biocompatibility and antibacterial activity}

Biocompatibility of synthesized of ZnS QDs was evaluated through hemolytic activity [43] against human erythrocytes and MTT assay [44] [(3-[4, 5-assay dimethylthiazole2-yl]-2, 5-diphenyl tetrazolium bromide), a yellow tetrazole against L929 mouse fibroblast cell lines. The antibacterial activity of ZnS QDs was performed in terms of zone of inhibition, minimum inhibitory concentration, minimum bactericidal concentration and killing kinetic assay $[45,46]$. The details of materials used and the description of all the assays are reported in Supplementary information.

\section{Results and discussion}

\section{Mechanism involved in the synthesis of ZnS QDs}

It has been observed that most of the green chemistry-synthesized nanoparticle reactions are carried out in the aqueous medium. In the present study, the suitability of the reaction in the water is probably because of the reaction between $\mathrm{Zn}^{+2}$ (borderline soft acid) and $\mathrm{S}^{-2}$ (soft base). According to the hard and soft acid and base (HSAB) theory, the reactions carried between a soft acid and a soft base give rise to a product having low-solubility product in the aqueous medium [2]. This helps in the separation of the required pure compounds easily from the solvent. The by-products formed during the reaction can be easily removed from the medium. Addition of D-glucose (capping agent) was done to restrain the size of the end product. The density functional theory (DFT) calculation (Supplementary section) showed that the attachment of the $\mathrm{ZnS}$ molecule is with the oxygen atom bonded to the fourth carbon of D-glucose molecule. The conformation manages to have the least energy associated with it $(-722,197.6382 \mathrm{kcal} / \mathrm{mol})$. The attachment of the $\mathrm{ZnS}$ molecule to the oxygen atom bonded to the third carbon may also be possible due to comparable bond energy associated with it (less by $0.2181 \mathrm{kcal} / \mathrm{mol}$ ). The plausible reaction mechanism is reported in Supplementary section. Prepared nano-material was subjected to various microscopic and spectroscopic characterization techniques.

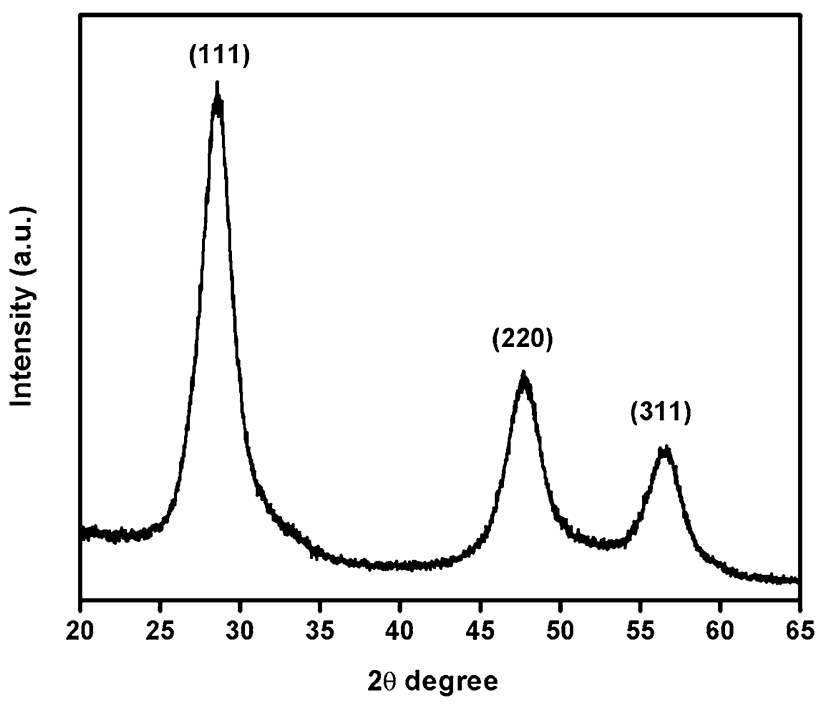

Fig. 1 Powder XRD pattern of ZnS nano-crystals revealing the corresponding Miller indices of diffraction planes

\section{Powder X-ray diffraction analysis}

This powerful technique gives accurate information about the zinc blende crystal structure of $\mathrm{ZnS}$ nanoparticles (Fig. 1). The broader FWHM of the peaks informs us about the generation of nanoparticles. The most intense peak was found along the plane (111), with the d-spacing $3.1 \AA$, indicating the formation of the majority of the nano-crystallites along this axis. Other prominent peaks were found for the planes (220) and (311) at the d-spacing $1.9 \AA$ and $1.6 \AA$, respectively.

The X-ray analysis reveals the identity of the cubic crystallites of $\mathrm{ZnS}$ quantum dots having FCC structure. The unit-cell edge parameter ' $a$ ' and the volume of each unit cell were calculated to be $539.96 \mathrm{pm}$ and $1.57 \times 10^{-22} \mathrm{~cm}^{3}$, respectively. Broadening of the XRD peaks indicates the smaller particle size of ZnS nanoparticles. The Scherrer formula (Eq. 1) reveals that $\beta$ (FWHM) is inversely proportional to $\tau$ (crystallite size). The actual broadening due to crystallite size, $\beta_{a}$, and strain are calculated after instrumental broadening, $\beta_{i}$, is deducted from the overall, observed broadening, $\beta_{o}$, considering Cauchy (Lorentzian) [47] (Eq. A) profile as follows:

$\beta a=\beta_{o}-\beta_{i}$

$\tau=\kappa \lambda / \beta \cos \theta$

The average grain $(\tau)$ size, $4.09 \mathrm{~nm}$, was calculated using Eq. (1). The lattice strain of the nanoparticles was calculated using Williamson and Hall model (Eq. 2).

$\beta_{h k l} \cos \theta=\kappa \lambda / L+4 \eta \sin \theta$ 
where $\beta_{h k l}$ denotes line broadening at the half of the intensity, $\theta$ Bragg angle (in degree), $\kappa$ shape factor, $\lambda \mathrm{X}$-ray wavelength, $L$ mean size of the particle, and $\eta$ lattice strain

The average value of lattice strain $(\eta)$ along all the 3 prominent planes calculated is 0.0258 . The highest strain of 0.0381 was found along the most intense peak in (111) plane. The increase in lattice strain is also attributed to the increased surface energy when the size of the particle is very small (QDs).

The specific surface area $(S)$ was also calculated with the help of Brunauer, Emmett and Teller (BET) method [48] (Eq. 3) from the powder XRD spectrum. Since the surfaceto-volume ratio of the nanoparticle is higher, its surface activity will enhance immensely.

$S_{\mathrm{BET}}=6000 / D_{\mathrm{p}} * \rho$

where $S_{\mathrm{BET}}$ denotes specific surface area, $D_{\mathrm{p}}$ size of the particles, and $\rho$ density of the material

To analyze the surface activity, the density of ZnS QDs $(\rho)$ is calculated as $4.11 \mathrm{~g} / \mathrm{cm}^{3}$. Calculation reveals the value of $\mathrm{S}_{\mathrm{BET}}$ as $356.93 \mathrm{~m}^{2} / \mathrm{g}$, and the higher value indicates its expected efficiency in terms of the extent of adsorption.

XRD data were further used for calculating the dislocation density $(\delta)$ of $\mathrm{ZnS}$ QDs per unit volume:

$\delta=15 \beta \cos \theta / 4 a D$

where $\delta$ denotes dislocation density, $\beta$ line broadening at the half of the intensity (FWHM-full width half maximum), $\theta$ Bragg angle (in degree), $a$ lattice edge parameter, and $D$ particle size.

The dislocation density for ZnS QDs along the highest intensity peak along (111) plane was calculated to be $6.40 \times 10^{14} \mathrm{~m}^{-2}$. The existence of dislocation density may be attributed to lattice strain which is observed more along (111) plane. The smaller the particle size, the higher will be the possibility of dislocations as they have more tendencies to stabilize their higher surface energy. Dislocations are basically the topological defects, which may be screw and edge, and have been visualized through HRTEM for ZnS QDs.

\section{High-resolution transmission electron microscope analyses}

HRTEM micrographs allow us to achieve the shape and size of each and every individual nano-crystallite in the most precise way. The lattice alignments, as well as their directions and defects, can also be detected with the help of this tool. Nanoparticles of $\mathrm{ZnS}$ ranging from 3 to $6 \mathrm{~nm}$ in diameter with spherical shape (larger surface energy) were observed in the scale of $5 \mathrm{~nm}$ (Fig. 2a inset). A large number of clusters of $\mathrm{ZnS}$ QDs (homogeneously distributed) were also observed in the range of $50 \mathrm{~nm}$ (Fig. 3). The average

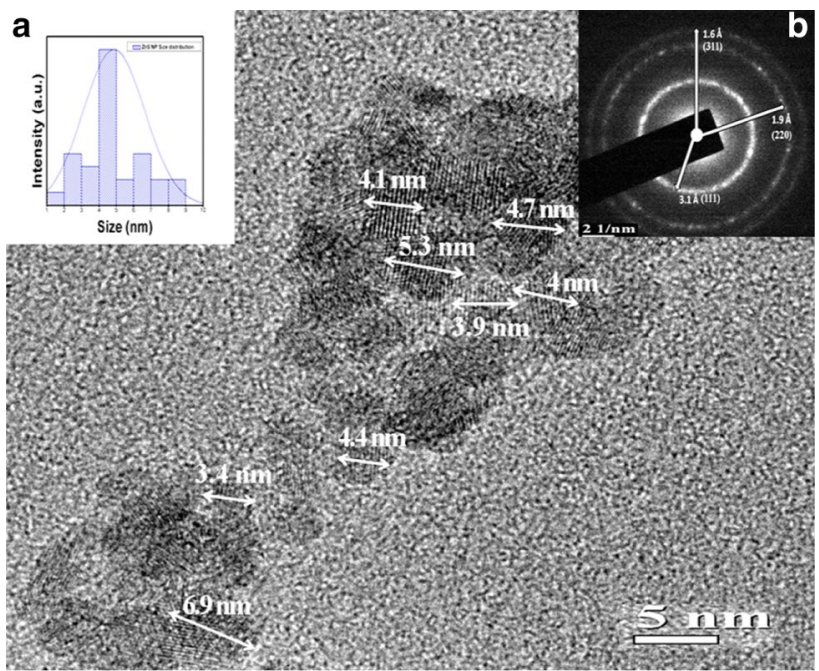

Fig. 2 HRTEM image of colloidal distribution of spherical-shaped $\mathrm{ZnS}$ QDs with a size distribution and $\mathbf{b}$ with SAED pattern

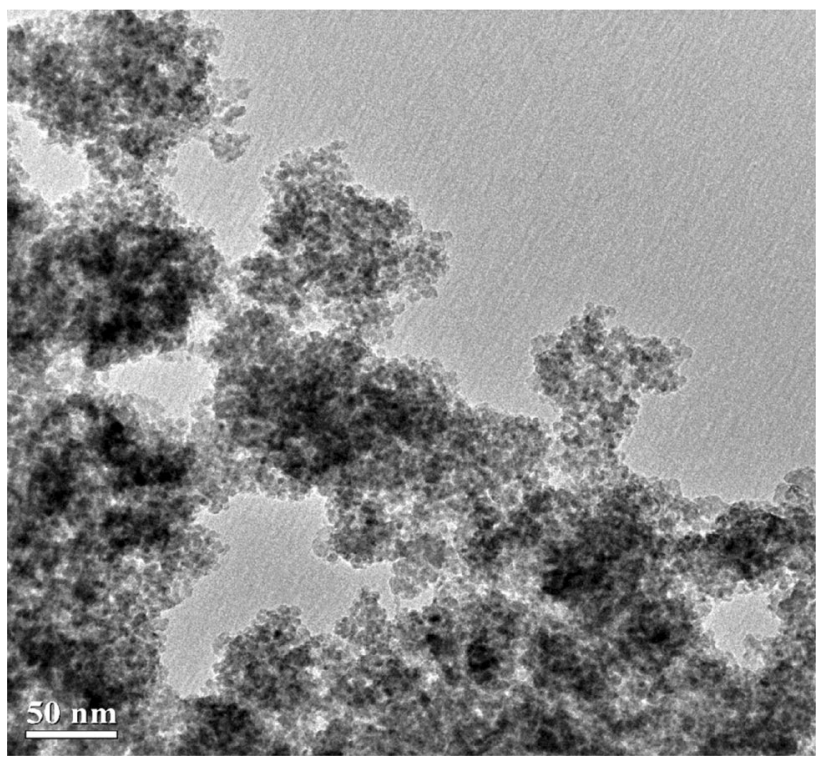

Fig. 3 TEM image exhibiting clustering of ZnS QDs on copper grid

particle size for around 20 nano-crystallites was recorded to be $4 \mathrm{~nm}$, which is in good agreement with the results revealed by the XRD analysis also. SAED (selected area electron diffraction) pattern clearly reveals the polycrystallinity of the ZnS QDs with the d-spacing (Fig. 2b inset) of $3.1 \AA, 1.9 \AA$ and $1.6 \AA$, which is in confirmation with the XRD results. The imprinting polycrystallinity with its every bright spot, observed in the SAED pattern, confirms the presence of nano-crystallites feature of $\mathrm{ZnS}$ QDs. The zigzag alignment of atoms in the FCC $\mathrm{ZnS}$ nanoparticle reveals the presence of planar stacking fault along the (200) plane, which is evident from (Fig. 4). The FFT pattern of 


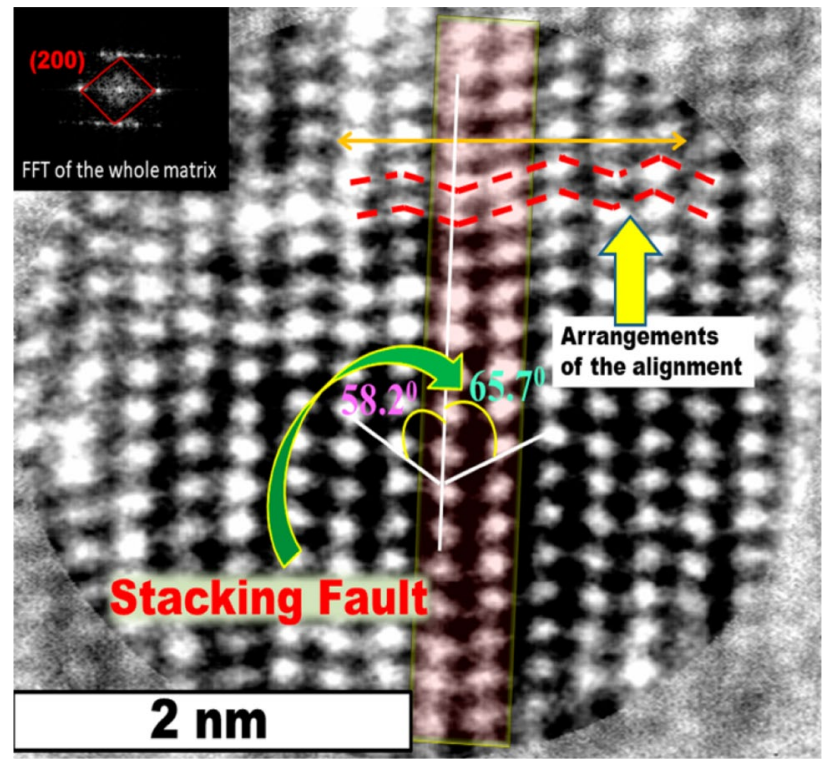

Fig. 4 Stacking fault (shaded area)

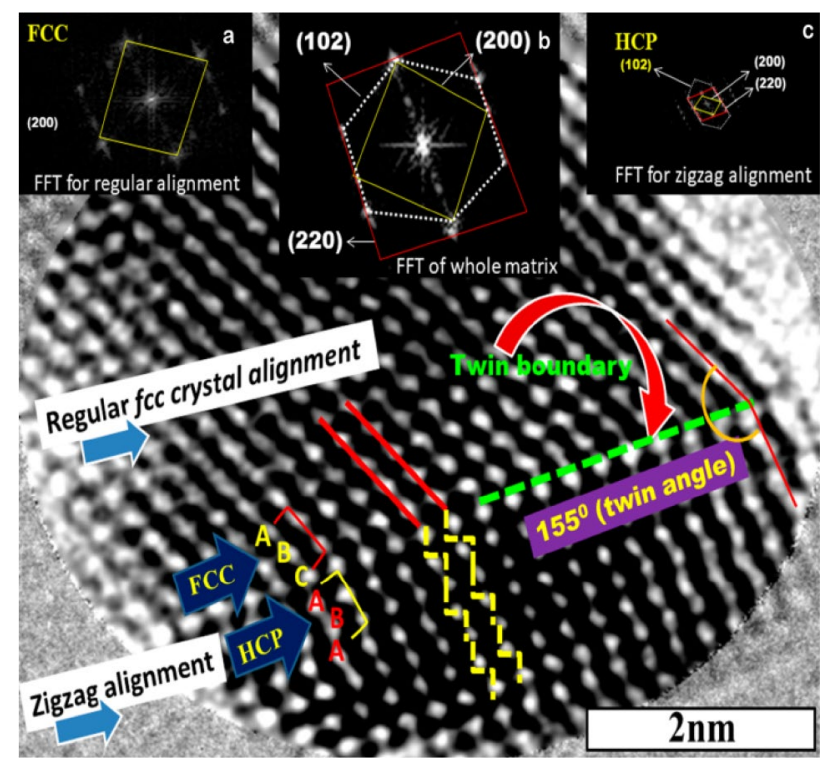

Fig. 5 Two differently aligned ( $c c p$ and $h c p$ ) planner conformations within the same grain

(200) plane is reported in Fig. 4 inset. The formation of zigzag alignment may be attributed to the occurrence of two partial dislocations of atoms in the respective planes. Using the ImageJ software, the angles of atoms in each alignment in both sides of the stacking fault were found to be $58.2^{\circ}$ and $65.7^{\circ}$. The presence of (102) plane (FFT of Fig. 5 inset) also speaks about the occurrence of the hexagonal plane $\left(\mathrm{d}_{102}=2.3 \AA\right)$. TEM micrographs also reveal the existence of twin boundary growth (Fig. 5) in $\mathrm{ZnS}$ nanoparticles. An angle of $155^{\circ}$ was calculated between the two differently

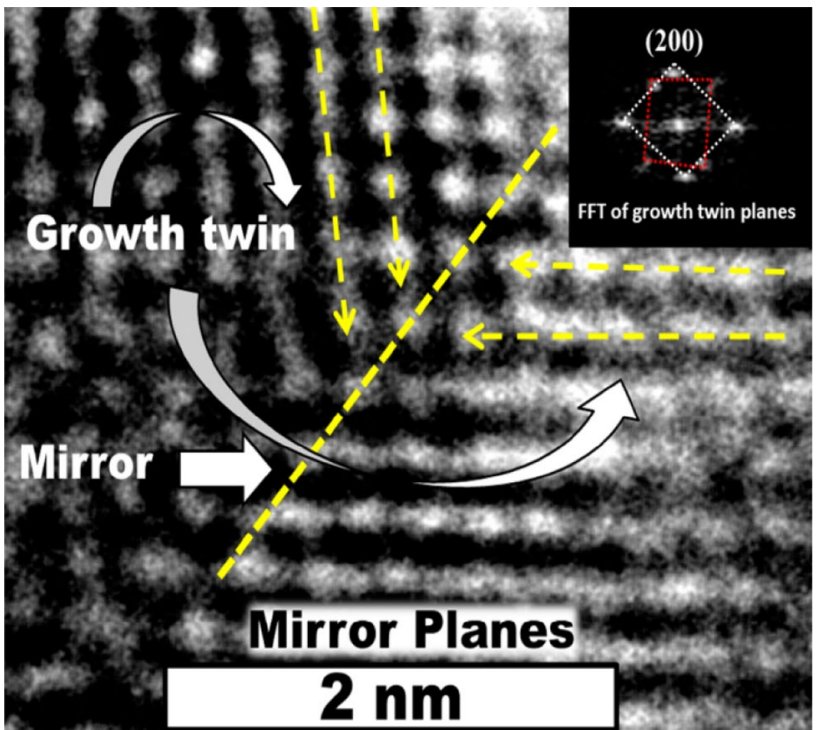

Fig. 6 Growth mirror twin planes

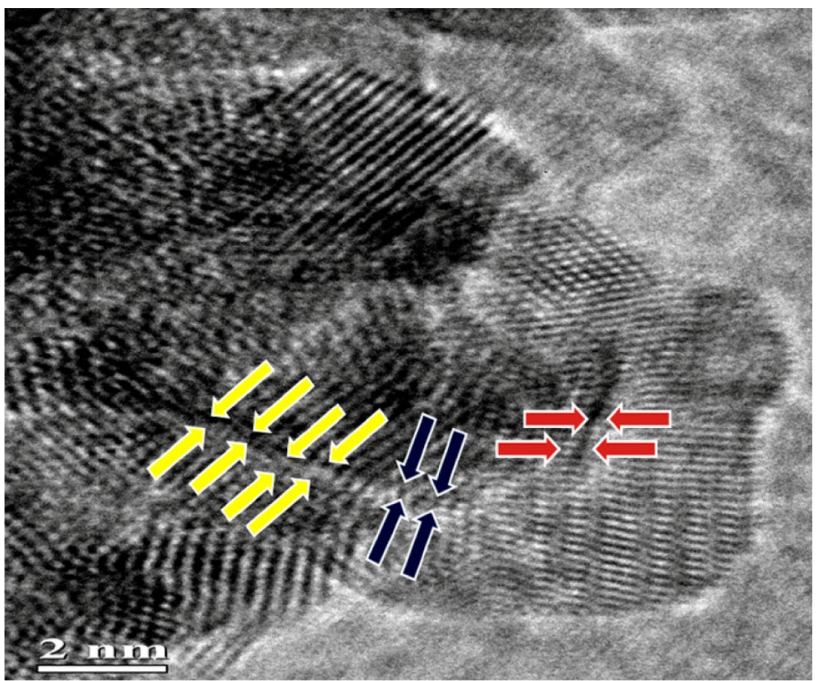

Fig. 7 Edge dislocation leading to indistinct grain boundary

aligned planes observed in the twin boundary area. The regular FCC (ccp) and zigzag (hcp) crystal alignments were observed in the area under investigation. The FFT patterns of the crystal alignments are reported in Fig. 5a, b, c inset.

The loss in contrast through (200) plane is probably due to the presence of stacking fault, which usually has been observed to occur during the synthesis of QDs [49]. From Fig. 6, it is observed that the twin growths tend to merge each other resulting in the formation of mirror images of each other. Such types of micro-twin growths can be 
pointed out in quite a number of QD alignments of $\mathrm{ZnS}$, where these localized defects try to form parallel planes at the junction of contact twin. Since the edge dislocation (Fig. 7) can be seen prominently in the alignments of $\mathrm{ZnS}$ nanoparticles, the grain boundary cannot be distinctly visualized.

\section{Absorption spectra}

The $\lambda_{\max }$ for the $\mathrm{ZnS}$ QDs was found to be at $314 \mathrm{~nm}$ (blue shift). Unlike conspicuous absorption peaks which can be observed for bulk materials, the formation of QDs of $\mathrm{ZnS}$ is signified relatively by broader peaks (Fig. 8).

This is attributed to the generation of variation in the band gap for each nano-sized particle of $\mathrm{ZnS}$. The optical band gap of the particles was found to be $3.95 \mathrm{eV}$. The higher value of the band gap of ZnS QDs by $0.37 \mathrm{eV}$ than the bulk cubic $\mathrm{ZnS}$ confirms the formation of nanoparticles in the solution. The particle size was calculated with the Brus Eq. (5) and found to be $5.8 \mathrm{~nm}$, which is in agreement with the absorption spectrum:

$E_{g(\mathrm{QD})}=E_{\mathrm{bulk}}+h^{2} / 8 R^{2}\left(1 / m_{e}^{*}+1 / m_{h}^{*}\right)-1.786 e^{2} / 4 \pi \varepsilon_{0} \varepsilon_{r} R$

where $E_{\text {gap }}$ denotes band gap energy of the bulk $\mathrm{ZnS}, m_{e}^{*}$ effective mass of the excited electron [50], $m_{h}^{*}$ effective mass of the electron-hole, $r$ radius of the particle, $h$ Planck's constant, $e$ charge of electron, $\varepsilon_{0}$ vacuum permittivity, and $\varepsilon_{r}$ dielectric constant of $\mathrm{ZnS}$.

The value of the third quantity in Eq. (5) is often neglected for semiconductors due to the high value of dielectric constant.

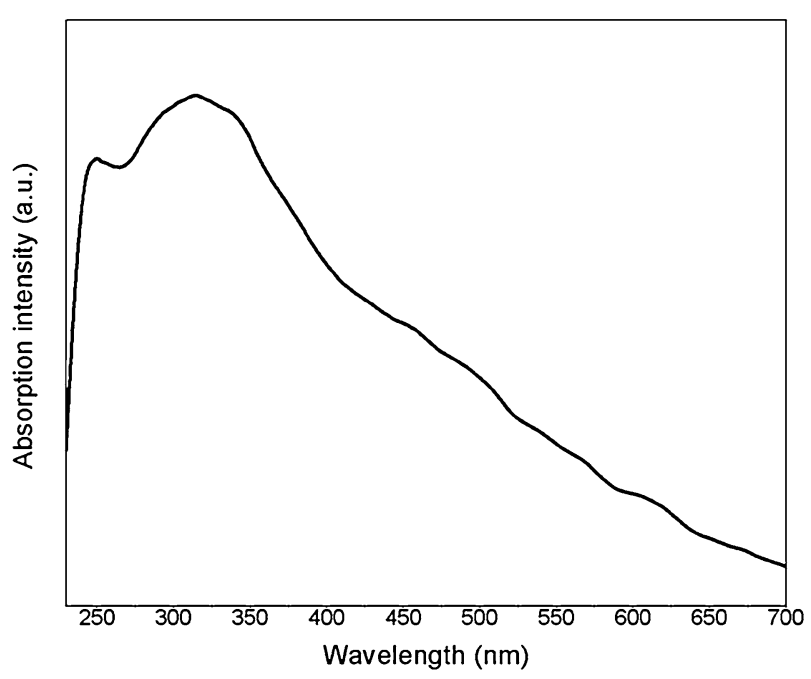

Fig. 8 UV-visible absorption spectra (314 nm) of colloidal ZnS QDs synthesized
Table 1 Comparative size of ZnS QDs calculated using different characterization techniques

\begin{tabular}{|c|c|c|c|c|}
\hline \multicolumn{3}{|c|}{ Average size of $\mathrm{ZnS}$ nanoparticle } & \multirow{2}{*}{$\begin{array}{l}\text { Optical band gap } \\
E=h c / \lambda\end{array}$} & \multirow{2}{*}{$\begin{array}{l}\text { Blue shift } \\
\Delta E\end{array}$} \\
\hline XRD & TEM & UV-visible & & \\
\hline $4.09 \mathrm{~nm}$ & $5 \mathrm{~nm}$ & $5.76 \mathrm{~nm}$ & $3.95 \mathrm{eV}$ & $0.37 \mathrm{eV}$ \\
\hline
\end{tabular}

The comparison of the particle size of $\mathrm{ZnS}$ nanoparticles calculated by different techniques is reported in Table 1 .

\section{Zeta potential}

The surface charge (zeta potential) of $\mathrm{ZnS}$ nanoparticles was found to be negative $(-9.2 \mathrm{mV})$, attributed to the fairly stable configuration of synthesized QDs.

\section{FTIR spectra}

The FTIR spectrum (Fig. 9) shows a strong peak at $649 \mathrm{~cm}^{-1}$, which is significant for $\mathrm{Zn}-\mathrm{S}$ (metal sulfide) bond. The other strong peaks at $1635 \mathrm{~cm}^{-1}$ and $3411 \mathrm{~cm}^{-1}$ reveal the presence of $\mathrm{H}_{2} \mathrm{O}$ bending and $-\mathrm{OH}$ stretching. The presence of a later peak confirms the presence of capping of D-glucose molecule. Another peak at $1010 \mathrm{~cm}^{-1}$ stands for $\mathrm{C}-\mathrm{O}$ stretching.

\section{Atomic force microscopy}

From the AFM topologies, large aggregated nanoparticles are observed. The aggregation may be due to the particle coalescing (Fig. 10). The darker and brighter portions in Figs. 10, 11 correspond to the valleys and peaks

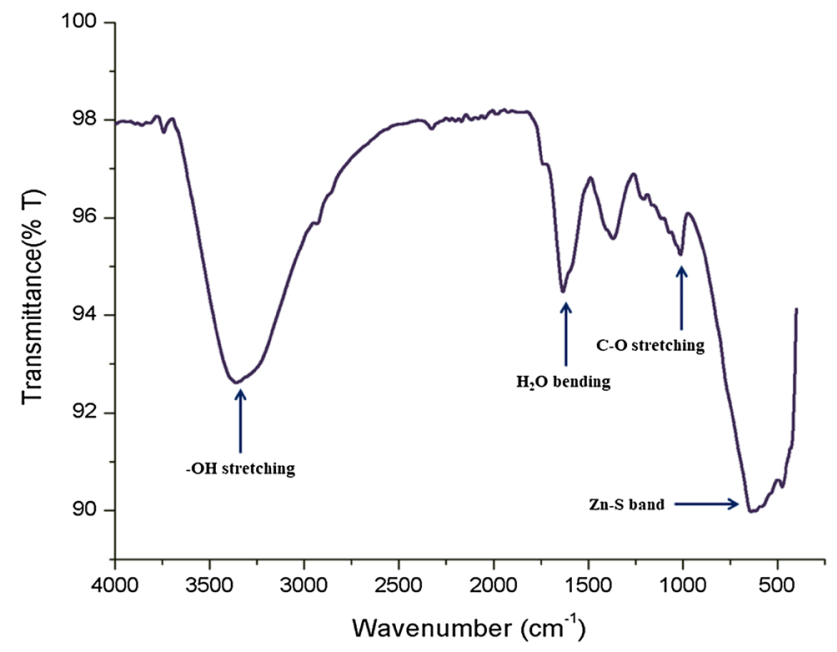

Fig. 9 FTIR spectra showing characteristic metal-sulfur bond as well as the interaction of $\mathrm{ZnS}$ QDs with D-glucose molecule as a capping agent 


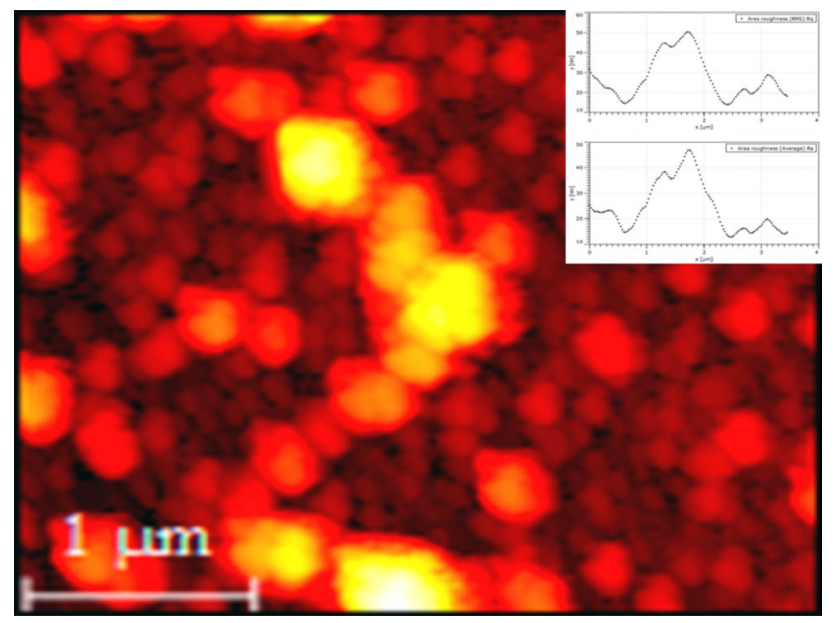

Fig. 10 Top view morphology of ZnS QDs thin film observed under AFM in dynamic mode

on the surface of the nano-sized thin film of ZnS QDs. The ratio of average roughness, root mean square $\left(R_{\mathrm{q}}\right)$ and average roughness $\left(R_{\mathrm{a}}\right)$ is found to be 1.33 , which is in accordance with the height distribution predicted by Gaussian for most of the engineering surface (1.31) [51]. The height symmetry of the surface of thin films can be understood by skewness $\left(R_{\mathrm{sk}}=1.68\right)$ (Table 2$)$. The positive $R_{\mathrm{sk}}$ value indicates the presence of a bumpy surface. Since the value is not much higher than zero, it relates to a nearly symmetrical distribution of peaks and valleys about the mean line position. The peakedness parameter, kurtosis $\left(R_{\mathrm{ku}}\right)$ (Table 2$)$, shows a value of 2.93 for the nano-sized thin film of ZnS QDs, which corresponds to the random distribution of peaks and valleys, known as mesokurtic behavior. The positive value of $R_{\mathrm{sk}}$ and $R_{\mathrm{ku}}$ reveals that the nano-sized $\mathrm{ZnS}$ thin films are suitable for tribological applications [52]. The maximum peak to valley height difference $\left(R_{t}=210.78 \mathrm{~nm}\right)$ has an important impact on the surface properties of thin films. It gives us the idea about the maximum roughness of the topology of the thin film of $\mathrm{ZnS}$ nanoparticles. Gwyddion free software was used to calculate the average thickness $(50 \pm 20 \mathrm{~nm})$ using AFM data of thin films, which is in good agreement with the thickness $(57 \mathrm{~nm})$ measured with the help of Filmetrics (Supplementary information). Since QD thin films (QDTFs) can absorb and convert harmful UV lights to use visible light, they can be used

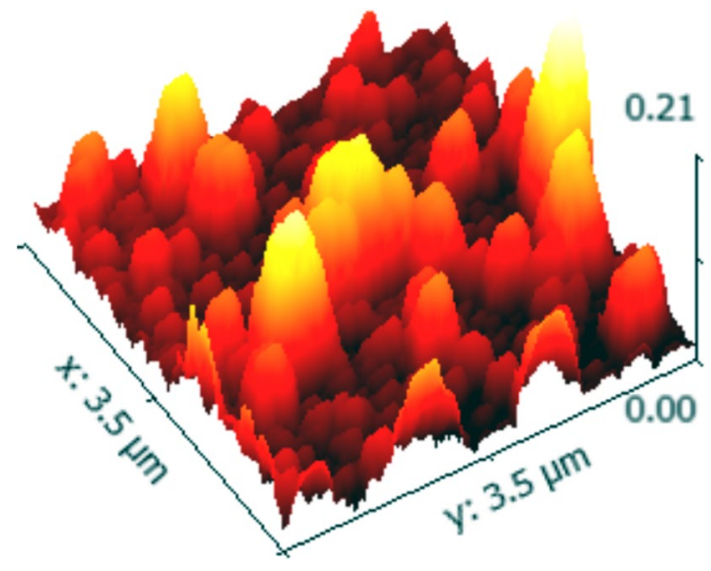

Fig. 11 3D view of Fig. $10 \mathrm{ZnS}$ QDs thin film observed under AFM

for the future fabrication of QDTF solar cells. These cells can expand the photoresponse range and therefore can enhance the photoelectric conversion efficiently [53].

\section{Biocompatibility analysis of green chemistry-synthesized ZnS nanoparticles (NPs)}

\section{Cytotoxicity against mammalian cell}

The synthesized ZnS NPs demonstrated noticeable biocompatibility as is evident from cytotoxicity (MTT) assay results. The tested NPs (up to $200 \mu \mathrm{g} / \mathrm{ml}$ concentration) did not induce any significant cytotoxicity toward L929 mouse fibroblastic cells even after $72 \mathrm{~h}$ of post-treatment. The synthesized ZnS NPs exhibited time- and concentrationdependent decrease in cell viability which is in the range between 99.60 and $78.23 \%$. This is also in agreement with the previous reports (Fig. 12) [54]. Even, with $200 \mu \mathrm{g} / \mathrm{ml}$ concentration and $72 \mathrm{~h}$ of incubation, the synthesized $\mathrm{ZnS}$ NPs did not induce any significant cytotoxicity to the tested mammalian cell. The higher percentage of mammalian cell viability demonstrated by the tested ZnS NPs may be attributed to repulsive interaction that mediated inefficient uptake of negatively charged ZnS NPs through negatively charged cell membrane [55]. Before further investigation of the synthesized ZnS NPs in preclinical and clinical settings, various biomedical applications and the high dose tolerance exhibited by the mammalian cell line for a prolonged duration (72 $\mathrm{h}$ or more hours) are very important.

Table 2 Characteristic roughness parameters of ZnS QDs thin film evaluated using AFM at 3.48 X $3.48 \mu \mathrm{m}^{\wedge^{2}}$ of the scan area

\begin{tabular}{lllllll}
\hline Average particle size & Average roughness $\left(R_{\mathrm{a}}\right)$ & Average roughness $\left(R_{\mathrm{q}}\right)(\mathrm{rms})$ & $\mathrm{Rq} / \mathrm{Ra}$ & $\begin{array}{l}\text { Skewness } \\
R_{\mathrm{sk}}\end{array}$ & $\begin{array}{l}\text { Kurtosis } \\
R_{\mathrm{ku}}\end{array}$ & $\begin{array}{l}\text { The maximum peak to valley } \\
\text { height difference }\left(R_{t}\right)\end{array}$ \\
\hline $56 \pm 10 \mathrm{~nm}$ & $24.97 \mathrm{~nm}$ & $33.28 \mathrm{~nm}$ & 1.33 & 1.68 & 2.93 & $210.78 \mathrm{~nm}$ \\
\hline
\end{tabular}




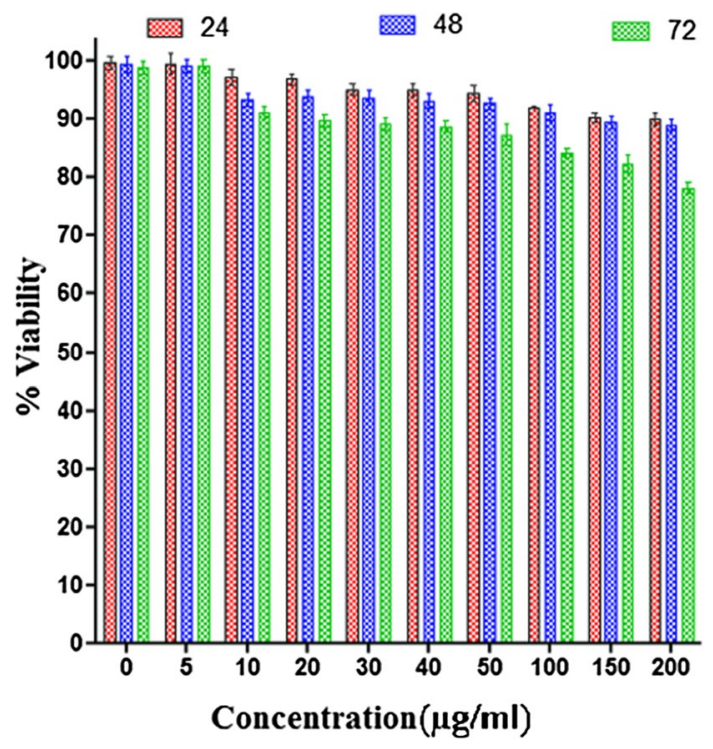

Fig. 12 Cytotoxicity evaluation (MTT) of ZnS NPs (The data are presented as mean \pm S.E. of five replicates)

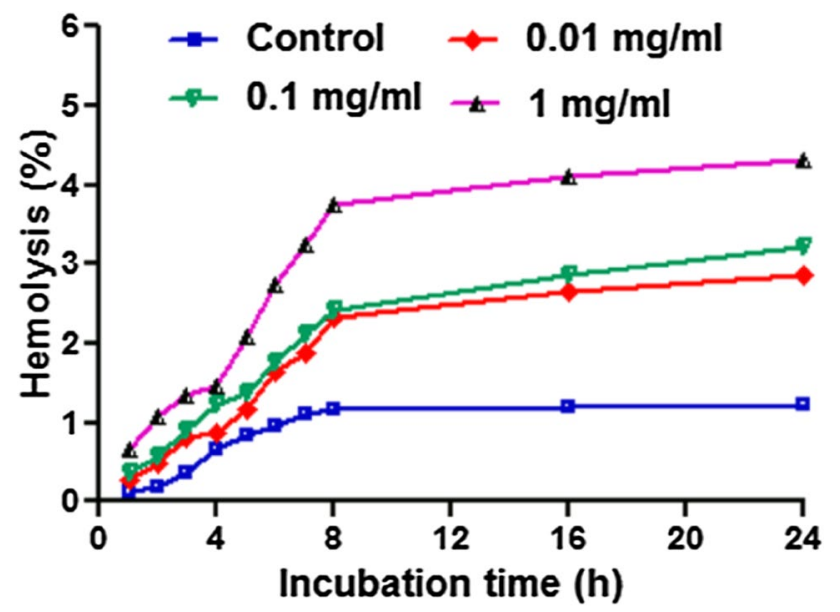

Fig. 13 Hemolysis of the RBCs incubated with different concentrations of the $\mathrm{ZnS}$ NPs at $37{ }^{\circ} \mathrm{C}$ temperature

\section{Hemolytic activity evaluation}

RBC constitutes $40-50 \%(\mathrm{v} / \mathrm{v})$ of human whole blood and is responsible for the transport of carbon dioxide and oxygen. Hemolysis refers to the release of hemoglobin due to the disintegration of the three-layered RBC membrane, which is considered one of the most crucial parameters for evaluation of biocompatibility of biomaterials. The tested $\mathrm{ZnS}$ NPs in a concentration ranging from 0.01 to $1 \mathrm{mg} / \mathrm{ml}$ demonstrated mild to moderate hemolysis up to incubation period of $24 \mathrm{~h}$ in a dose- and time-dependent manner. For all the tested concentration of ZnS NPs, as compared to control, the RBCs maintained its membrane integrity and did not lyse significantly up to even $4 \mathrm{~h}$ of time point, whereas from $8 \mathrm{~h}$ onward, all the tested concentrations of ZnS NPs started inducing, a mild to moderate level of lysis of erythrocytes, reaching $2.86 \%, 3.21 \%$ and $4.32 \%$ for $0.01 \mathrm{mg} / \mathrm{ml}, 0.1 \mathrm{mg} /$ $\mathrm{ml}$ and $1 \mathrm{mg} / \mathrm{ml}$ concentrations, respectively (Fig. 13). The negative surface charge of the RBC repulsed the ZnS NPs and obstructed interaction, which may be attributed to the higher level of hemocompatibility of the tested ZnS NPs. The mild or moderate hemolytic activity exhibited by the ZnS NPs may be due to the hydrophobic interaction that mediated damage of RBC membrane and subsequent release of hemoglobin [56]. These preliminary data on hemocompatibility of the synthesized ZnS NPs will help to standardize, in future, the bio-safe concentration for its prospective biomedical applications.

\section{In vitro Antibacterial activity of $\mathrm{ZnS}$ nanoparticles (NPs)}

To explore antibacterial effectiveness of the synthesized $\mathrm{ZnS}$ NPs, zone of inhibition (ZOI), minimum inhibitory concentration (MIC), minimum bactericidal concentration (MBC) and time-kill assay studies were performed against seven pathogenic bacterial strains. The tested ZnS NPs demonstrated noticeable zone of inhibition with a concentrationdependent increase in antibacterial activity against all the tested bacterial pathogens (Table 2). It was observed that in spite of possessing thicker peptidoglycan layer, grampositive bacteria exhibited more susceptibility toward the tested ZnS NPs as compared to gram-negative bacteria; this may be due to the absence of an outer membrane. We conclude that the outer lipopolysaccharide membrane present in gram-negative bacteria offers a significant obstruction toward nanoparticle penetration or diffusion and consequently protects the cellular ultra-structures from $\mathrm{ZnS}$ NPsmediated disturbances and subsequent dysfunction of the cell. S. aureus and P. aeruginosa were found to be most and least susceptible to the tested ZnS NPs. The pathogenic bacterial strains demonstrated variable MIC/MBC values ranging from 75 to $125 \mu \mathrm{g} / \mathrm{ml}$ for gram-positive bacteria and 100 to $150 \mu \mathrm{g} / \mathrm{ml}$ for gram-negative bacterial pathogens, respectively (Table 3 ). Since $S$. aureus and B. subtilis were found to be most susceptible bacterial strains, these were further evaluated for killing kinetics assay. The tested ZnS NPs demonstrated significant enhanced killing in terms of reduction in CFU count of $S$. aureus and B. subtilis in 4-, 8- and 12-h time points as compared to the non-treated strains (Fig. 14). All experiments were done in triplicate and results are expressed in mean, and standard deviations were negligible.

In order to exhibit antibacterial functions, NPs need to undergo interaction with the bacterial cell. The prominent 
Table 3 Antibacterial activity profile of $\mathrm{ZnS} N P s$ in terms of zone of inhibition (ZOI), minimum inhibitory concentration (MIC) and minimum bactericidal concentration $(\mathrm{MBC})$

\begin{tabular}{llllll}
\hline Sl. no & Bacterial strains & $100 \mu \mathrm{g} / \mathrm{ml}$ & $\begin{array}{l}\text { ZOI }(\mathrm{cm}) \\
200 \mu \mathrm{g} / \mathrm{ml}\end{array}$ & $300 \mu \mathrm{g} / \mathrm{ml}$ & MIC/MBC $(\mu \mathrm{g} / \mathrm{ml})$ \\
\hline 1. & Bacillus cereus & 1.3 & 2.5 & 3.1 & $100 / 125$ \\
2. & Bacillus subtilis & 1.6 & 2.3 & 2.8 & $75 / 125$ \\
3. & Klebsiella pneumonia & 1.1 & 2.1 & 2.7 & $125 / 150$ \\
4. & Escherichia coli & 1.9 & 2.6 & 3 & $100 / 150$ \\
5. & Staphylococcus aureus & 2.1 & 2.9 & 3.4 & $75 / 100$ \\
6. & Pseudomonas aeruginosa & 0.7 & 1 & 1.4 & $125 / 150$ \\
7. & Staphylococcus epidermidis & 1.8 & 2.7 & 2.9 & $100 / 125$ \\
\hline
\end{tabular}

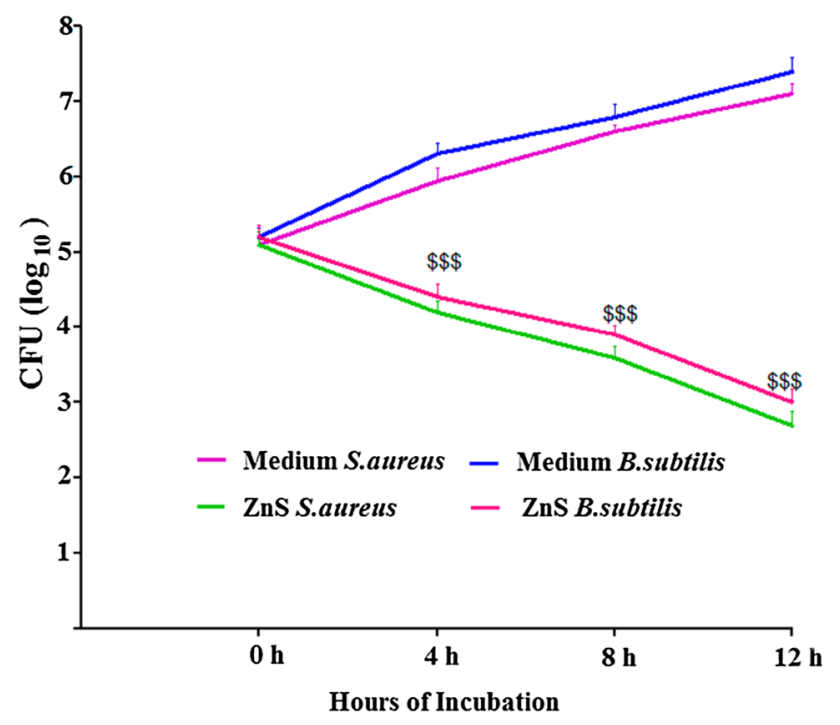

Fig. 14 Time-kill assay of S. aureus (MTCC 3160) and B. subtilis (MTCC 441) were incubated with ZnS NPs. Surviving CFU at selected time points is shown. All the results were expressed in mean \pm S.D. $(n=3)$. $\$ \$ \$ p<0.001$, comparison of medium $S$. aureus and medium B. subtilis with $\mathrm{ZnS}$ QDs $S$. aureus and $\mathrm{ZnS}$ B. subtilis at different time intervals

accepted forms of interactions can be established by van der Waals forces [57], electrostatic forces [58], hydrophobic interactions [59] and ligand-receptor interactions [60]. While the NPs, capped with biocompatible cappers, are capable of forming such interactions with the bacterial cell membrane, they are able to cross the cell membrane and get into the metabolic pathways, thereby influencing the function and the shape of the cell membrane. The high antibacterial performance of the synthesized $\mathrm{ZnS}$ QDs is due to their very small size $(\sim 5 \mathrm{~nm})$, i.e., within $10 \mathrm{~nm}$ range as observed in the present study. It is an established fact that the lesser the size $(<10 \mathrm{~nm})$ of the nanoparticles, the better is their diffusion efficacy to penetrate through the pores of the cell membrane, and hence, they can easily go inside a microbial cell [61]. The synthesized ZnS QDs are expected to readily access the interior of the bacterial cell and can interact with the basic components of the cell (viz. DNA, ribosome, lysosomes, etc.). These may lead to the generation of oxidative stress, protein deactivation, electrolyte balance disorder, enzyme inhibition and changes in cell membrane permeability inside the cell and finally cause death to the cell [62-64]. Conclusively, it can easily be understood that it is the advantage of the size $(\sim 5 \mathrm{~nm})$ of the synthesized $\mathrm{ZnS}$ QDs $(<10 \mathrm{~nm})$ that makes these nanoparticles (QDs) very promising as antibacterial agent. The rapid killing efficiency of the tested ZnS NPs is thus helpful in impeding biofilm formation at a faster pace. Findings of these experiments unveil the positive prospective attribute of the synthesized ZnS NPs utility in biomedical applications as anti-infective agents and hold tremendous potential in the application in superficial antibacterial therapeutics, implant coating, as well as in antibacterial textile material development with various advantageous functionalities.

\section{Conclusion}

We have presented a simple, time economic, cost-effective, reproducible and therefore successful method of synthesizing ZnS QDs. The method is an environmentally benign process, fulfilling the principles of green chemistry. The quantum dot thin films (QDTF) with its specified surface morphologies can absorb and transform harmful UV light to usable visible light efficiently, making them suitable for solar cell applications. The synthesized 2-6-nm nanoparticles were specially found to be biocompatible and also proficient antibacterial agents over a wide range of antibacterial studies. The synthesized QDs did not exert any adverse effect on mammalian cells.

Acknowledgements The research scholar is grateful to University Grants Commission, New Delhi, India, for providing the financial support. The authors are thankful to Centre for Advanced Studies in Chemistry, NEHU, Shillong.

\section{Compliance with ethical standards}

Conflict of interest The authors declare that they have no conflict of interest. 
Open Access This article is distributed under the terms of the Creative Commons Attribution 4.0 International License (http://creativeco mmons.org/licenses/by/4.0/), which permits unrestricted use, distribution, and reproduction in any medium, provided you give appropriate credit to the original author(s) and the source, provide a link to the Creative Commons license, and indicate if changes were made.

\section{References}

1. Li, H., Shih, W.Y., Shih, W.-H.: Synthesis and characterization of aqueous carboxyl-capped CdS quantum dots for bioapplications. Ind. Eng. Chem. Res. 46, 2013-2019 (2007). https://doi. org/10.1021/ie060963s

2. Jing, L., Kershaw, S.V., Li, Y., et al.: Aqueous based semiconductor nanocrystals. Chem. Rev. 116, 10623-10730 (2016). https:// doi.org/10.1021/acs.chemrev.6b00041

3. Dahl, J.A., Maddux, B.L.S., Hutchison, J.E.: Toward greener nanosynthesis. Chem. Rev. 107, 2228-2269 (2007). https://doi. org/10.1021/cr050943k

4. Lu, Y.B., Li, L., Su, S.C., et al.: A novel TiO2nanostructure as photoanode for highly efficient CdSe quantum dot-sensitized solar cells. RSC Adv. 7, 9795-9802 (2017). https://doi.org/10.1039/ c6ra26029b

5. Wang, J., Li, Y., Shen, Q., et al.: Mn doped quantum dot sensitized solar cells with power conversion efficiency exceeding $9 \%$. J. Mater. Chem. A 4, 877-886 (2016). https://doi.org/10.1039/c5ta0 $9306 \mathrm{f}$

6. Nozik, A.J.: Exciton multiplication and relaxation dynamics in quantum dots: applications to ultrahigh-efficiency solar photon conversion. Inorg. Chem. 44, 6893-6899 (2005). https://doi. org/10.1021/ic0508425

7. Rühle, S., Shalom, M., Zaban, A.: Quantum-dot-sensitized solar cells. Chem Phys Chem 11, 2290-2304 (2010). https://doi. org/10.1002/cphc.201000069

8. Salant, A., Shalom, M., Hod, I., et al.: quantum dot sensitized solar cells with improved efficiency prepared using electrophoretic deposition. ACS Nano 4, 5962-5968 (2010). https://doi. org/10.1021/nn1018208

9. Beard, M.C.: Multiple exciton generation in semiconductor quantum dots. J. Phys. Chem. Lett. 2, 1282-1288 (2011). https://doi. org/10.1021/jz200166y

10. Hanna, M.C., Nozik, A.J.: Solar conversion efficiency of photovoltaic and photoelectrolysis cells with carrier multiplication absorbers. J. Appl. Phys. 100, 074510 (2006). https://doi. org/10.1063/1.2356795

11. Semonin, O.E., Luther, J.M., Choi, S., et al.: Peak external photocurrent quantum efficiency exceeding $100 \%$ via MEG in a quantum dot solar cell. Science 334, 1530-1533 (2011). https://doi. org/10.1126/science.1209845

12. Kamat, P.V., Tvrdy, K., Baker, D.R., Radich, J.G.: Beyond photovoltaics: semiconductor nanoarchitectures for liquid-junction solar cells. Chem. Rev. 110, 6664-6688 (2010). https://doi.org/10.1021/ cr100243p

13. Nozik, A.: Quantum dot solar cells. Physica E 14, 115-120 (2002). https://doi.org/10.1016/s1386-9477(02)00374-0

14. Kamat, P.V.: Quantum dot solar cells. the next big thing in photovoltaics. J. Phys. Chem. Lett. 4, 908-918 (2013). https://doi. org/10.1021/jz400052e

15. Yu, W.W., Qu, L., Guo, W., Peng, X.: Experimental determination of the extinction coefficient of CdTe, CdSe, and CdS nanocrystals. Chem. Mater. 15, 2854-2860 (2003). https://doi.org/10.1021/ $\mathrm{cm} 034081 \mathrm{k}$

16. Wang, J., Li, Y., Shen, Q., et al.: Mn doped quantum dot sensitized solar cells with power conversion efficiency exceeding $9 \%$. J.
Mater. Chem. A 4, 877-886 (2016). https://doi.org/10.1039/c5ta0 9306f

17. Kershaw, S.V., Jing, L., Huang, X., et al.: Materials aspects of semiconductor nanocrystals for optoelectronic applications. Mater Horizons 4, 155-205 (2017). https://doi.org/10.1039/c6mh00469e

18. Kamat, P.V.: Meeting the clean energy demand: nanostructure architectures for solar energy conversion. J. Phys. Chem. C 111, 2834-2860 (2007). https://doi.org/10.1021/jp066952u

19. Michalet, X.: Quantum dots for live cells, in vivo imaging, and diagnostics. Science 307, 538-544 (2005). https://doi. org/10.1126/science.1104274

20. Talapin, D.V., Lee, J.-S., Kovalenko, M.V., Shevchenko, E.V.: Prospects of colloidal nanocrystals for electronic and optoelectronic applications. Chem. Rev. 110, 389-458 (2010). https:// doi.org/10.1021/cr900137k

21. Kamat, P.V.: Photochemistry on nonreactive and reactive (semiconductor) surfaces. Chem. Rev. 93, 267-300 (1993). https:// doi.org/10.1021/cr00017a013

22. Thompson, T.L., Yates, J.T.: $\mathrm{TiO}_{2}$-based photocatalysis: surface defects, oxygen and charge transfer. Top. Catal. 35, 197-210 (2005). https://doi.org/10.1007/s11244-005-3825-1

23. Harris, C., Kamat, P.V.: Photocatalysis with cdse nanoparticles in confined media: mapping charge transfer events in the subpicosecond to second timescales. ACS Nano 3, 682-690 (2009). https://doi.org/10.1021/nn800848y

24. Tachikawa, T., Fujitsuka, M., Majima, T.: Mechanistic insight into the $\mathrm{TiO}_{2}$ photocatalytic reactions: design of new photocatalysts. J. Phys. Chem. C 111, 5259-5275 (2007). https://doi. org/10.1021/jp069005u

25. http://www.google.com/patents/US7916065. Accessed 29 Mar 2011

26. NASA https://www.nasa.gov/feature/goddard/2017/nasa-andmit-collaborate-to-develop-space-based-quantum-dot-spect rometer. Accessed 14 Feb 2017

27. Wegner, K.D., Hildebrandt, N.: Quantum dots: bright and versatile in vitro and in vivo fluorescence imaging biosensors. Chem. Soc. Rev. 44, 4792-4834 (2015). https://doi.org/10.1039/c4cs0 0532e

28. Xing, Y., Chaudry, Q., Shen, C., et al.: Bioconjugated quantum dots for multiplexed and quantitative immunohistochemistry. Nat. Protoc. 2, 1152-1165 (2007). https://doi.org/10.1038/nprot .2007 .107

29. Yezhelyev, M.E.V., Al-Hajj, A., Morris, C., et al.: In situ molecular profiling of breast cancer biomarkers with multicolor quantum dots. Adv. Mater. 19, 3146-3151 (2007). https://doi.org/10.1002/ adma.200701983

30. Smith, A.M., Dave, S., Nie, S., et al.: Multicolor quantum dots for molecular diagnostics of cancer. Exp. Rev. Mol. Diagn. 6, 231-244 (2006). https://doi.org/10.1586/14737159.6.2.231

31. Elward, J.M., Chakraborty, A.: Effect of dot size on exciton binding energy and electron-hole recombination probability in cdse quantum dots. J. Chem. Theory Comput. 9, 4351-4359 (2013). https://doi.org/10.1021/ct400485s

32. Franceschetti, A., Zunger, A.: Direct pseudopotential calculation of exciton coulomb and exchange energies in semiconductor quantum dots. Phys. Rev. Lett. 78, 915-918 (1997). https://doi. org/10.1103/physrevlett.78.915

33. Kasap, S.O., Capper, P.: Springer Handbook of Electronic and Photonic Materials. Springer, Boston (2007)

34. Alivisatos, A.P.: Semiconductor clusters, nanocrystals, and quantum dots. Science 271, 933-937 (1996). https://doi.org/10.1126/ science. 271.5251 .933

35. Nozik, A.J., Beard, M.C., Luther, J.M., et al.: Semiconductor quantum dots and quantum dot arrays and applications of multiple exciton generation to third-generation photovoltaic solar cells. 
Chem. Rev. 110, 6873-6890 (2010). https://doi.org/10.1021/cr900 289f

36. Form EIA-63B, Annual Photovoltaic Module/Cell Manufacturers Survey, Energy Information Administration, USA, 2006

37. Ginley, D., Green, M.A., Collins, R.: Solar Energy conversion toward 1 terawatt. MRS Bull. 33, 355-364 (2008). https://doi. org $/ 10.1557 / \mathrm{mrs} 2008.71$

38. King, R.R., Law, D.C., Edmondson, K.M., et al.: 40\% efficient metamorphic GaInP/GaInAs/Ge multijunction solar cells. Appl. Phys. Lett. 90, 183516 (2007). https://doi.org/10.1063/1.2734507

39. Dimroth, F., Kurtz, S.: High-efficiency multijunction solar cells. MRS Bull. 32, 230-235 (2007). https://doi.org/10.1557/mrs20 07.27

40. Luque, A., Martí, A., Nozik, A.J.: Solar cells based on quantum dots: multiple exciton generation and intermediate bands. MRS Bull. 32, 236-241 (2007). https://doi.org/10.1557/mrs2007.28

41. Green, M.A.: Third Generation Photovoltaics: Advanced Solar Energy Conversion. Springer, Berlin (2006)

42. Martí, A.: Next Generation Photovoltaics: High Efficiency Through Full Spectrum Utilization. Institute of Physics Publishing, Bristol (2004)

43. Kalita, S., Kandimalla, R., Devi, B., et al.: Dual delivery of chloramphenicol and essential oil by poly- $\varepsilon$-caprolactone-Pluronic nanocapsules to treat MRSA-Candida co-infected chronic burn wounds. RSC Adv. 7, 1749-1758 (2017). https://doi.org/10.1039/ c6ra26561h

44. Kandimalla, R., Kalita, S., Choudhury, B., et al.: Fiber from ramie plant (Boehmeria nivea): a novel suture biomaterial. Mater. Sci. Eng. C 62, 816-822 (2016). https://doi.org/10.1016/j. msec.2016.02.040

45. Kotoky, J., Kandimalla, R., Kalita, S., et al.: Chloramphenicol encapsulated in poly- $\varepsilon$-caprolactone-pluronic composite: nanoparticles for treatment of MRSA-infected burn wounds. Int. J. Nanomed. (2015). https://doi.org/10.2147/ijn.s75023

46. Kalita, S., Kandimalla, R., Sharma, K.K., et al.: Amoxicillin functionalized gold nanoparticles reverts MRSA resistance. Mater. Sci. Eng. C 61, 720-727 (2016). https://doi.org/10.1016/j. msec.2015.12.078

47. General Area Detector Diffraction System (GADDS) User Manual (2005). Bruker Advanced X-Ray Solutions. https://depts.washi ngton.edu/moleng/wordpress/wp-content/uploads/2015/03/ GADDS_Manual.pdf. Accessed Jan 2005

48. Brunauer, S., Emmett, P.H., Teller, E.: Adsorption of gases in multimolecular layers. J. Am. Chem. Soc. 60, 309-319 (1938). https://doi.org/10.1021/ja01269a023

49. Murray, C.B., Norris, D.J., Bawendi, M.G.: Synthesis and characterization of nearly monodisperse $\mathrm{CdE}(\mathrm{E}=$ sulfur, selenium, tellurium) semiconductor nanocrystallites. J. Am. Chem. Soc. 115, 8706-8715 (1993). https://doi.org/10.1021/ja00072a025

50. Manzoor, K., Johny, S., Thomas, D., et al.: Bio-conjugated luminescent quantum dots of doped $\mathrm{ZnS}$ : a cyto-friendly system for targeted cancer imaging. Nanotechnology 20, 065102 (2009). https://doi.org/10.1088/0957-4484/20/6/065102

51. Thomas, T.R.: Rough Surfaces. Imperial College Press, London (1999)

52. Kumar, B.R., Rao, T.S.: AFM Studies on surface morphology, topography and texture of nanostructured zinc aluminum oxide thin films. Dig. J. Nanomater. Biostruct. 7, 1881-1889 (2012)
53. Chen, Y., Li, S., Huang, L., Pan, D.: Single-step direct fabrication of luminescent $\mathrm{Cu}$-doped $\mathrm{Zn}_{\mathrm{x}} \mathrm{Cd}_{1-\mathrm{x}} \mathrm{S}$ quantum dot thin films via a molecular precursor solution approach and their application in luminescent, transparent, and conductive thin films. Nanoscale 6 , 9640-9645 (2014). https://doi.org/10.1039/c4nr02237h

54. Jayasree, A., Sasidharan, S., Koyakutty, M., et al.: Mannosylated chitosan-zinc sulphide nanocrystals as fluorescent bioprobes for targeted cancer imaging. Carbohydr. Polym. 85, 37-43 (2011). https://doi.org/10.1016/j.carbpol.2011.01.034

55. Chen, L., Mccrate, J.M., Lee, J.C.-M., Li, H.: The role of surface charge on the uptake and biocompatibility of hydroxyapatite nanoparticles with osteoblast cells. Nanotechnology 22, 105708 (2011). https://doi.org/10.1088/0957-4484/22/10/105708

56. Li, S., Guo, Z., Zhang, Y., et al.: Blood compatibility evaluations of fluorescent carbon dots. ACS Appl. Mater. Interfaces. 7, 19153-19162 (2015). https://doi.org/10.1021/acsami.5b04866

57. Armentano, I., Arciola, C.R., Fortunati, E., Ferrari, D., Mattioli, S., Amoroso, C.F., Rizzo, J., Kenny, J.M., Imbriani, M., Visai, L.: The interaction of bacteria with engineered nanostructured polymeric materials: a review. Sci. World J. 2014, 1-18 (2014). https://doi.org/10.1155/2014/410423

58. Li, H., Chen, Q., Zhao, J., Urmila, K.: Enhancing the antimicrobial activity of natural extraction using the synthetic ultrasmall metal nanoparticles. Sci. Rep. (2015). https://doi.org/10.1038/ srep11033

59. Luan, B., Huynh, T., Zhou, R.: Complete wetting of graphene by biological lipids. Nanoscale. 8, 5750-5754 (2016). https://doi. org/10.1039/C6NR00202A

60. Gao, W., Thamphiwatana, S., Angsantikul, P., Zhang, L.: Nanoparticle approaches against bacterial infections. Wiley Interdiscip. Rev.: Nanomed. Nanobiotechnol. 6, 532-547 (2014). https://doi. org/10.1002/wnan.1282

61. Mukha, I.P., Eremenko, A.M., Smirnova, N.P., Mikhienkova, A.I., Korchak, G.I., Gorchev, V.F., Chunikhin, A.Y.: Antimicrobial activity of stable silver nanoparticles of a certain size. Appl. Biochem. Microbiol. 49, 199-206 (2013). https://doi.org/10.1134/ S0003683813020117

62. Xu, Y., Wei, M.-T., Ou-Yang, H.D., Walker, S.G., Wang, H.Z., Gordon, C.R., Guterman, S., Zawacki, E., Applebaum, E., Brink, P.R., Rafailovich, M., Mironava, T.: Exposure to TiO2 nanoparticles increases Staphylococcus aureus infection of HeLa cells. J. Nanobiotechnol. (2016). https://doi.org/10.1186/s1295 1-016-0184-y

63. Shrivastava, S., Bera, T., Roy, A., Singh, G., Ramachandrarao, P., Dash, D.: Characterization of enhanced antibacterial effects of novel silver nanoparticles. Nanotechnology. 18, 225103 (2007). https://doi.org/10.1088/0957-4484/18/22/225103

64. Yang, W., Shen, C., Ji, Q., An, H., Wang, J., Liu, Q., Zhang, Z.: Food storage material silver nanoparticles interfere with DNA replication fidelity and bind with DNA. Nanotechnology. 20, 085102 (2009). https://doi.org/10.1088/0957-4484/20/8/085102

Publisher's Note Springer Nature remains neutral with regard to jurisdictional claims in published maps and institutional affiliations. 